\title{
Uncertainties shroud medical isotope supply
}

I $\mathrm{t}$ was not a milestone greeted with much fanfare, but the end of March marked the demise of the Non-reactor-based Isotope Supply Contribution Program (NISP), under which the federal government had sunk \$35 million into four projects aimed at determining whether there was an alternative means of generating the technetium-99m needed for roughly $80 \%$ of the 1.5 million nuclear medicine procedures performed annually in Canada.

The NISP was created in the aftermath of extended shutdowns of the National Research Universal (NRU) reactor in Chalk River, Ontario between 2007 and 2010. With hospitals scrambling to obtain medical isotopes in the wake of a global technetium shortage, a government-appointed Expert Review Panel on Medical Isotope Production was struck to investigate supply options for Canada and it recommended that more players be introduced to the med- ical isotope distribution chain, that the federal government work with other countries to better coordinate worldwide production and distribution of medical isotopes and that Canada eventually shift to making isotopes with low-enriched uranium targets and build a new multipurpose reactor (www .cmaj.ca/lookup/doi/10.1503/cmaj.109 -3127). The government's response was to create the NISP to determine whether it would be best to develop a new method of producing isotopes for example, by using cyclotrons that utilized low-enriched uranium (www.cmaj.ca/lookup/doi/10.1503/cmaj .109-3187).

Most academic researchers regard the NISP as a rushed affair. But the four projects did at least confirm the technical feasibility of using particle accelerators to generate technetium$99 \mathrm{~m}$ without using weapons-grade uranium. The Cross Cancer Centre in Edmonton, Alberta, launched a clini- cal trial in the fall of 2011 injecting patients with technetium-99m manufactured from an on-site cyclotron, while a team led by Tri-University Meson Facility at the University of British Columbia used the backdrop of the annual meeting of the American Association for the Advancement of Science to laud its production of isotopes using a cyclotron as a "major milestone" in resolving the precarious global supply.

The launch of a new era for Canada's 12 existing cyclotrons once the NRU is shut down permanently in 2016 ?

Well, perhaps.

The federal government responded somewhat tepidly to the developments by announcing in its recent budget that $\$ 17$ million would be provided over two years for Natural Resources Canada "to further advance the development of alternatives to existing isotope production technologies and help secure the supply of medical isotopes

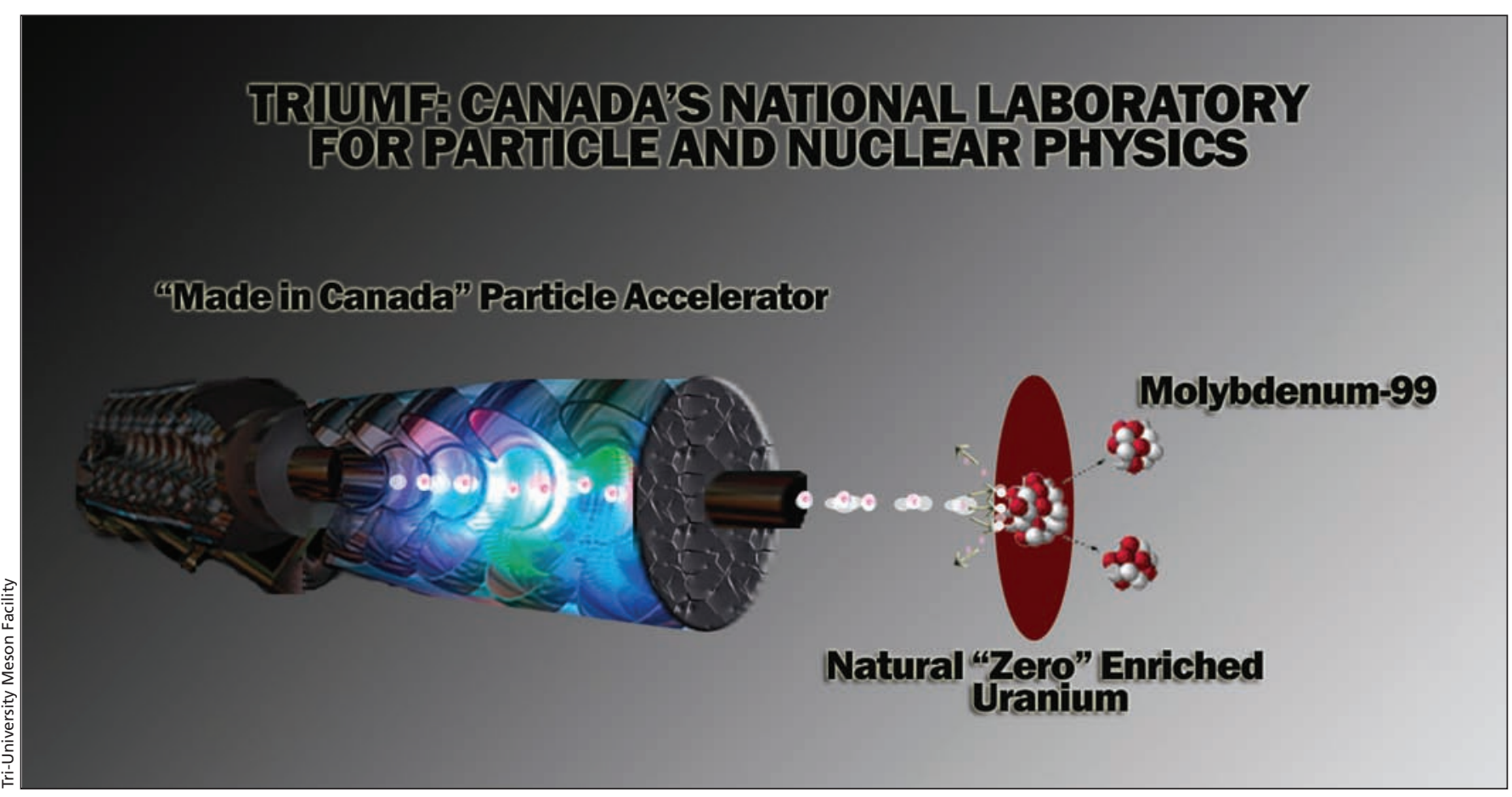

The Tri-University Meson Facility says the advantages of using photo-fission accelerator techniques to generate medical isotopes include the use of natural or depleted uranium targets, the ability to shut down the accelerator as desired, the ease of decommissioning of an accelerator and the scalability of the technology. 
for Canadians" (www.cmaj.ca/lookup /doi/10.1503/cmaj.109-4174).

The latter could almost mean anything, says Éric Turcotte, clinical head of the Sherbrooke Molecular Imaging Centre in Quebec.

"We don't know what the government wants," says Turcotte, a member of the expert review panel. "They want a solution, but they don't want it ready to go on the market. They just want the proof of concept. After that, there is no research proposed by them."

Turcotte's imaging centre, home to a $19-\mathrm{MeV}$ cyclotron, recently added a 24-MeV counterpart to ensure continuous, high-volume production of a wide range of isotopes, including technetium-99m. He's convinced Canada's existing cyclotrons can easily match the isotope output of the NRU.

It would be costly, though, while imposing an administrative burden on cyclotron operators, who'd have to ensure compliance with Good Manufacturing Practices set by Health Canada. In the past, that burden has fallen on radiopharmacies that delivered molybdenum to imaging centres, which, in turn, converted the element into technetium- 99 .

But those added costs have to be weighed against the rising cost of reactor-generated isotopes, Turcotte argues, adding that the latter will be driven up by the recent American prohibitions against the export of highly enriched uranium. He adds that it takes five times as much low-enriched uranium to produce the same amount of molybdenum for distribution to imaging centres.

As for whether international facilities can meet Canadian needs once the NRU is shutdown is unclear. While two other international reactors are also scheduled to close, new ones are planned in France and the Netherlands. But as Canada's experience with the overdesigned and abandoned Multipurpose Applied Physics Lattice Experiment reactors proved (www.cmaj.ca /lookup/doi/10.1503/cmaj.080320), the timeline for nuclear start-ups can be unpredictable.

Isotope supplier MDS Nordion has begun importing isotopes from Russia as part of broader, "multi-source" approach to isotope supply, says Tanya Pobuda, senior manager of corporate communications. "We are actively working to assess and develop other supplemental and long-term potential sources of Mo99 [molybdenum] from both reactor and non-reactor projects."

Equally problematic are the potential costs of internationally sourced isotopes. International production facilities have long been government subsidized but the Organisation for Economic Cooperation and Development's Nuclear Energy Agency urged in 2011 that cost recovery, including reactor maintenance and replacement expenses, be the new standard for pricing (www.oecd-nea .org/med-radio/reports/MO-99.pdf).
Does that make the cost of cyclotronproduced isotopes more feasible?

No one knows for certain.

A financial analysis of the new isotope-supply models hasn't been completed, says Terry Ell, clinical coordinator of the Nuclear Medicine Program at Foothills Hospital in Calgary, Alberta. "Nobody has a crystal ball."

But Ell, who represents the Canadian Association of Medical Radiation Technologists on a Canadian Agency for Drugs and Technology in Health committee that has been struck to examine the best way for Canada to use medical isotopes and introduce new imaging technologies, says there's no doubt isotope demand will keep rising or that the need for isotopes will never disappear. "Thirty years ago I recall quite clearly that nuclear medicine was going to not exist anymore, because CT [computed tomography] was coming on line. That hasn't happened. We've always remained viable, and we've been able to evolve and change with the requirements of the environment."

That leaves Canada in the position of having to make some manner of choice, Turcotte says. "The future is very foggy. But one thing is for sure: we are going in a direction where technetium may be hard to find. We need to have a solution ready to go on-line by 2016." - Tim Lougheed, Ottawa, Ont.

CMAJ 2012. DOI:10.1503/cmaj.109-4217 